\title{
Longitudinal study on work related and individual risk factors affecting radiating neck pain
}

\author{
E Viikari-Juntura, R Martikainen, R Luukkonen, P Mutanen, E-P Takala, H Riihimäki
}

\begin{abstract}
Objectives-To study the effects of work related and individual factors affecting radiating neck pain.

Methods-A longitudinal study was carried out with repeated measurements. A total of $\mathbf{5 1 8 0}$ Finnish forest industry workers replied to a questionnaire survey in 1992 (response rate $75 \%$ ). Response rates to follow up questionnaires in 1993, 1994, and 1995 were $83 \%, 77 \%$, and $90 \%$, respectively. The outcome variable was the number of days with radiating neck pain during the preceding 12 months with three levels $(<8,8-30,>30$ days $)$. The generalised estimating equations method was used to fit a marginal model and a transition model was used in a predictive analysis.

Results-Items showing associations with radiating neck pain in both analyses were sex, age, body mass index, smoking, duration of work with a hand above shoulder level, mental stress, and other musculoskeletal pains. In the transition model, radiating neck pain in a previous questionnaire was included in the model. Although it was a strong predictor, the variables already mentioned retained their significance.

Conclusion-Programmes targeted to reduce physical load at work, mental stress, being overweight, and smoking could potentially prevent radiating neck pain. (Occup Environ Med 2001;58:345-352)
\end{abstract}

Keywords: neck disorder; mental stress; physical work load

Many epidemiological studies have been carried out to assess environmental and individual risk factors for neck disorders. ${ }^{1-7}$ There is evidence from both cross sectional and longitudinal studies that work with abducted arms, ${ }^{18}$ forward flexion of the neck, ${ }^{8}$ and repetitive movements of the hands or fingers ${ }^{59}$ increase the risk of various neck disorders. Little is known about the intensity, frequency, or duration of the exposures associated with increased risk. To prevent neck disorders such information is necessary.

The quality of the assessment of physical load factors is essential in studies on musculoskeletal disorders. Objective measurements are considered more valid than subjective assessments. Practical circumstances and financial constraints may, however, preclude the use of objective assessment. Subjective assessment methods by questionnaire have been recently validated. ${ }^{10}{ }^{11}$ The results have shown that the questionnaire method is valid for some physical load factors at work-such as duration of sitting, walked distance, frequency of lifting loads heavier than $5 \mathrm{~kg}$, duration of forward flexion of the trunk each day, working with a hand above shoulder level, and squatting or kneeling.

As well as physical load factors psychological and work organisational factors have been associated with neck disorders and symptoms. ${ }^{12}$ These associations have been mostly found in cross sectional studies. ${ }^{34}$ In a prospective study, Pietri-Taleb et al found that psychological distress and personality factors had some predictive value for neck trouble among a group of male workers, but the associations were complex and occupation specific. ${ }^{6}$ In a 10 year follow up study, social relations among men, and work control among the women predicted a change in the disorders of the neck, shoulder, and upper limb. ${ }^{13}$ The occurrence of neck pain and neck disorders increases with age until late middle age and decreases thereafter. They are more common among women than among men. ${ }^{3}$

In a follow up study the incidence or recurrence of a clearly defined disease should be studied. The problem with the neck is that we lack generally accepted diagnostic criteria for common neck disorders. In this situation we have to use various symptoms or pain syndromes as the outcome. Such outcomes often have many categories, and their statistical analysis has not been straightforward.

We carried out a longitudinal study with four repeated questionnaires among workers in a large forest industry enterprise. As well as analyzing the data with a marginal model, we wanted to do a predictive analysis (transition model), in which all information from a previous year was used to predict radiating pain. The purpose of our study was to investigate the effects of work related and individual factors on radiating neck pain.

\section{Methods}

STUDY POPULATION

A total of 7000 blue and white collar workers of a large forest industry enterprise in Finland was selected for the study. This group consisted of all workers in mechanical and chemical forest industry processes and their maintenance tasks, foremen, technical designers, laboratory staff, and office clerks. A questionnaire on musculoskeletal pain and potential risk factors was posted to all by the occupational health service of the enterprise in March 1992. Two reminders were sent to non-respondents. Altogether $75 \%$ of the subjects returned the 
questionnaire. A few subjects with rheumatoid arthritis and part time workers were excluded, leaving 5180 subjects in the study cohort. There were 3899 men and 1281 women. The mean ages of the men and women were 41.8 (SD 9.6) and 43.4 (SD 9.2) years, respectively. Follow up questionnaires were posted in March 1993, 1994, and 1995 to those who had responded to the previous questionnaire. Response rates were $83 \%, 77 \%$, and $90 \%$, respectively. The corresponding numbers of subjects were 4283,3312 , and 2984 , and the percentages of the original sample were $62 \%$, $48 \%$, and $43 \%$, respectively.

The younger subjects replied less often than the older ones and the men slightly less often than the women. Those who had finished work after the preceding questionnaire replied less often than those who were still employed. Of the workers aged less than 55 years, 93\%-97\% were employed in the company during the questionnaire surveys in 1993-5. Half of those older than 54 years in 1992 had finished work in 1993, and most had done so before the last year of follow up. There was no difference between the respondents and non-respondents in the occurrence of radiating neck pain in the previous year.

QUESTIONNAIRE

A modified version of the Nordic Questionnaire $^{14}$ was used to investigate pain in the following body regions: neck (pain radiating to the upper extremity and local pain were investigated separately); shoulder; forearm and hand; low back (sciatic pain, lumbago, and other types of local pain separately). Body shaped models were used to denote the anatomical area in question. The outcome in this study was radiating neck pain. The exact wording of the question was as follows: "Estimate the total number of days you have had neck pain radiating to the upper extremity during the preceding 12 months." The original question had five categories: 0 days, 1-7 days, 8-30 days, $>30$ days but not daily, daily. In the analysis, we combined the first two categories, because we think that some days with neck pain does not indicate a neck disorder. The last two categories were combined due to the few subjects with daily pain. Accordingly, a three category variable was used ( $0-7$ days (healthy), 8-30 days (mild pain), >30 days (severe pain)).

In the 1992 questionnaire there were 14 questions on physical load factors at work, nine on work characteristics, and 28 on individual factors. ${ }^{15}$ Eleven questions on physical load factors, all nine questions on work characteristics, and 24 questions on individual factors were repeated in the 1994 questionnaire and most questions were also repeated in the 1993 and 1995 questionnaire. Based on an earlier study with the 1992 and 1993 data $^{15}$ the following 17 variables were selected for the analysis as explanatory variables:

Physical load factors at work

- Physical strenuousness of work (five categories)
- Squatting or kneeling at work (hours/day, four categories)

- Working with the trunk forward flexed (hours/day, four categories)

- Amount of twisting movements of the trunk during a workday (four categories)

- Working with hand above shoulder level (hours/day, four categories)

Work characteristics ${ }^{16}$

- Mental strenuousness of work (five categories)

- Balance of work demands (influence on work, possibility to use knowledge and skills, scoring of both questions from 1 to 5 , sum score variable)

- Overload at work (difficulty at work, hurry at work, scoring of both from 1 to 5 , sum score variable)

Individual factors

- Sex

- Age in 1992 (four categories)

- Working in the target enterprise at the time of the questionnaire (yes, no)

- Body mass index (weight $/$ height $^{2}$, four categories)

- Frequency of physical exercise (times/week, six categories)

- Smoking (non-, ex-, current smoker)

- Mental stress (five categories)

- Self assessed ability to work during the coming 5 years with regard to musculoskeletal health (no problems, problems possible, problems likely, used only in the transition model)

- Other musculoskeletal pains (severe pain in the following body areas: local neck pain; shoulder pain; forearm and hand pain; sciatic pain; lumbago; other local low back pain. Each pain scored 1, sum score range from 0 to 6 ).

The questions concerning postures of body parts were accompanied by body shaped models to illustrate the postures. The validity of three questions on working postures (squatting or kneeling, forward flexion of the trunk, and a hand above shoulder level) has already been studied and found to be moderate. ${ }^{11}$ The questions on the postures were included only in the 1992 and 1994 questionnaire. Because changes between 1992 and 1994 were reported by less than $25 \%$ of the subjects, we decided to use the 1992 values also for 1993 and the 1994 values also for 1995 .

The non-respondents did not differ from the respondents for most explanatory variables. The only exception was self assessed ability to work, the non-respondents reporting about 1.5 times as often as the respondents that they will have difficulties at work during the coming 5 years due to musculoskeletal health.

STATISTICAL METHODS

There are three important generalised linear models for longitudinal data with repeated measurements: marginal models, transition models, and random effect models. ${ }^{17}{ }^{18}$ In this study we applied the first two of these. 
Marginal models are appropriate when inferences about the population average are the focus. In most cases they are useful for epidemiological studies. In marginal models as well as marginal expectation of outcome, the correlation between the measurements can also be modelled. The marginal expectation is modelled in each assessment and the marginal regression coefficients have the same interpretation as those from a traditional cross sectional analysis. We used the generalised estimating equations method ${ }^{19}{ }^{20}$ to fit the marginal models.

In the transition model the outcome can be predicted on the basis of explanatory variables and all available information of previous outcomes. In these models the correlation of the repeated observations is dealt with by treating previous outcomes as additional explanatory variables and by calculating robust variance estimates. An advantage of these models is that the interactions can also be tested between the previous outcome and the explanatory variables. Both marginal models and transition models can use all available information - that is, if a subject is dropped from the study, his or her earlier data can be used in the analysis.

The outcome variable was radiating neck pain with three levels $(0-7,8-30,>30$ days). The explanatory variables were the physical load factors, work characteristics, and individual variables already listed. All explanatory variables except sex and age were time dependent. For some categorical variables, classes with small numbers were combined. Sum score variables were categorised. The effect of calendar time was also assessed. Interactions between physical load factors and work organisational factors, and physical load factors and selected individual factors (sex, age, body mass index, and mental stress) were of primary interest and were tested for when these variables were significant in the main effects model. Also interactions were tested between physical load factors and those between sex and age. With both methods, backward elimination strategy was used to construct the main effects model. Then, the interactions of interest between the variables in the main effects model were added to the model and the significant ones were included. A 5\% level was considered to be significant.

\section{Marginal model}

In our longitudinal study we had repeated measurements from each person and therefore the correlation between them must be taken into account. In this analysis our main interest

Table 1 Radiating neck pain in 1992 and 1995

\begin{tabular}{|c|c|c|c|c|c|c|c|c|}
\hline & \multicolumn{8}{|l|}{1995} \\
\hline & \multicolumn{2}{|c|}{ Healthy } & \multicolumn{2}{|c|}{ Mild } & \multicolumn{2}{|c|}{ Severe } & \multicolumn{2}{|l|}{ All } \\
\hline & $n$ & $\%$ & $n$ & $\%$ & $n$ & $\%$ & $n$ & $\%$ \\
\hline \multicolumn{9}{|l|}{ 1992: } \\
\hline Healthy $(67 \%)$ & 1562 & 85 & 170 & 9 & 118 & 6 & 1850 & 100 \\
\hline Mild (13\%) & 175 & 50 & 107 & 31 & 65 & 19 & 347 & 100 \\
\hline Severe $(20 \%)$ & 175 & 31 & 129 & 23 & 256 & 46 & 560 & 100 \\
\hline All $(100 \%)$ & 1912 & 69 & 406 & 15 & 439 & 16 & 2757 & 100 \\
\hline
\end{tabular}

was in the marginal expectation, and the correlation was a nuisance. Moreover, the generalised estimating equations method gives consistent parameter estimates and their variances even if the correlation structure is misspecified, given that the missing values generating mechanism is missing completely at random. ${ }^{20}$ However, the better the specified correlation approximates the true correlation, the better is the efficiency of the parameter estimates. We chose an exchangeable correlation structure to describe the dependencies between the measurements, meaning that the correlation between the measurements was constant between the time lags. Robust variance estimates were used in the calculation of confidence intervals for the parameters. The generalised estimating equations method $^{19}$ in the SUDAAN program ${ }^{21}$ was used to fit the proportional odds model to assess the effects of the explanatory variables on the ordered categorical outcome. The validity of the proportional odds assumption - that is, the homogeneity of the odds ratios across all possible cut off points of the response-was confirmed by fitting separate models with logit link function to both dichotomised responses with the same explanatory variables.

\section{Transition model}

In the Markov transition model (logistic model with proportional odds assumption) for longitudinal data analysis, ${ }^{19}$ the response in a previous questionnaire was included as an additional explanatory variable. We applied the first order Markov chain - that is, only the previous responses were used as explanatory variables. To ascertain a proper temporal relation between the exposures and the outcome, we lagged the exposures by 1 year. The 1992 exposures and outcome were used to predict the 1993 outcome, the 1993 exposures and outcome were used to predict the 1994 outcome, etc. S-Plus software with Design library was used. ${ }^{22}$ The transition model was fitted with the lrm function of the Design library. Robust SEs of the parameter estimates were calculated with ROBCOV and ANOVA functions to test the significance. The pairwise interactions of primary interest already listed were studied. Moreover, interactions with the response from the previous year were of special interest, as such interactions suggest different effects for incident and persistent neck pain.

\section{Results}

In $1992,67 \%$ of the subjects were healthy, $13 \%$ had mild, and $20 \%$ severe radiating neck pain (table 1). In 1995, the proportions of the healthy workers and those with mild pain were slightly higher and the proportion of those with severe pain was slightly lower.

In the first questionnaire survey in 1992, radiating neck pain showed associations with sex, age, physically strenuous work, squatting or kneeling, forward flexion of the trunk, twisting of the trunk, working with a hand above shoulder level, mental strenousness of work, balance of work demands, overload at work, 
Table 2 Distributions of the subjects in the different categories of radiating neck pain according to explanatory variables in $1992(n=5180)$

\begin{tabular}{|c|c|c|c|c|c|c|}
\hline \multirow[b]{3}{*}{ Explanatory variable } & \multicolumn{6}{|c|}{ Radiating pain } \\
\hline & \multicolumn{2}{|l|}{ None } & \multicolumn{2}{|c|}{ Moderate } & \multicolumn{2}{|c|}{ Severe } \\
\hline & $n$ & $\%$ & $n$ & $\%$ & $n$ & $\%$ \\
\hline \multicolumn{7}{|l|}{ Sex: } \\
\hline Male & 2522 & 68 & 493 & 13 & 687 & 19 \\
\hline Female & 673 & 55 & 199 & 16 & 355 & 29 \\
\hline \multicolumn{7}{|l|}{ Age $(y)$ : } \\
\hline$<35$ & 860 & 76 & 154 & 14 & 110 & 10 \\
\hline $35-44$ & 1151 & 69 & 258 & 15 & 264 & 16 \\
\hline $45-54$ & 942 & 57 & 223 & 13 & 502 & 30 \\
\hline $55-64$ & 242 & 52 & 57 & 12 & 166 & 36 \\
\hline \multicolumn{7}{|c|}{ Physical strenuousness of work: } \\
\hline Not at all & 490 & 77 & 56 & 9 & 88 & 14 \\
\hline Rather light & 906 & 69 & 203 & 15 & 207 & 16 \\
\hline Somewhat strenuous & 999 & 64 & 218 & 14 & 336 & 22 \\
\hline Rather strenuous & 502 & 57 & 136 & 16 & 235 & 27 \\
\hline Very strenuous & 281 & 54 & 78 & 15 & 165 & 31 \\
\hline \multicolumn{7}{|c|}{ Squatting or kneeling at work (h/day): } \\
\hline Not at all & 1110 & 67 & 215 & 13 & 330 & 20 \\
\hline$<0.5$ & 1024 & 67 & 225 & 15 & 273 & 18 \\
\hline $0.5-1$ & 625 & 63 & 151 & 15 & 211 & 22 \\
\hline$>1$ & 417 & 58 & 96 & 13 & 209 & 29 \\
\hline \multicolumn{7}{|c|}{ Working with the trunk flexed forward ( $h /$ day): } \\
\hline$>1$ & 1913 & 70 & 370 & 13 & 471 & 17 \\
\hline $1-2$ & 419 & 65 & 102 & 16 & 121 & 19 \\
\hline$>2$ & 830 & 57 & 210 & 14 & 424 & 29 \\
\hline \multicolumn{7}{|c|}{ Twisting movements of the trunk during a work day: } \\
\hline Not at all & 168 & 84 & 20 & 10 & 13 & 6 \\
\hline Little & 1444 & 73 & 237 & 12 & 290 & 15 \\
\hline Moderate & 1075 & 62 & 260 & 15 & 410 & 23 \\
\hline Much & 498 & 50 & 172 & 18 & 320 & 32 \\
\hline Working with a hand abov & $\mathrm{el}(\mathrm{h} / \mathrm{da}$ & & & & & \\
\hline$<0.5$ & 1929 & 69 & 392 & 14 & 470 & 17 \\
\hline $0.5-1$ & 742 & 65 & 158 & 14 & 245 & 21 \\
\hline$>1$ & 490 & 53 & 134 & 14 & 304 & 33 \\
\hline Mental strenuousness of $\mathrm{w}$ & & & & & & \\
\hline Not at all or rather light & 1111 & 72 & 186 & 12 & 244 & 16 \\
\hline Somewhat strenuous & 1463 & 63 & 336 & 15 & 502 & 22 \\
\hline Rather strenuous & 512 & 59 & 139 & 16 & 222 & 25 \\
\hline Very strenuous & 99 & 51 & 28 & 14 & 67 & 35 \\
\hline Balance of work demands: & & & & & & \\
\hline Good (score 2-4) & 930 & 71 & 156 & 12 & 219 & 17 \\
\hline Moderate (score 5-6) & 1600 & 64 & 381 & 15 & 511 & 21 \\
\hline Poor (score 7-10) & 647 & 59 & 150 & 14 & 300 & 27 \\
\hline Overload at work: & & & & & & \\
\hline Not at all (score 2-4) & 793 & 72 & 129 & 12 & 172 & 16 \\
\hline Little (score 5-6) & 1779 & 65 & 391 & 14 & 565 & 21 \\
\hline Definite (score 7-10) & 602 & 57 & 171 & 16 & 292 & 27 \\
\hline Body mass index $\left(\mathrm{kg} / \mathrm{m}^{2}\right)$ : & & & & & & \\
\hline$<23.0$ & 815 & 71 & 159 & 14 & 180 & 15 \\
\hline $23.0-25.9$ & 1195 & 67 & 235 & 13 & 362 & 20 \\
\hline $26.0-28.9$ & 738 & 61 & 189 & 15 & 288 & 24 \\
\hline$\geqslant 29.0$ & 403 & 59 & 96 & 14 & 189 & 27 \\
\hline Frequency of physical exer & eek): & & & & & \\
\hline$<2$ & 1133 & 65 & 254 & 14 & 365 & 21 \\
\hline $2-3$ & 1198 & 65 & 256 & 14 & 390 & 21 \\
\hline$>3$ & 824 & 65 & 175 & 14 & 268 & 21 \\
\hline Smoking: & & & & & & \\
\hline Non-smoker & 1314 & 66 & 283 & 14 & 390 & 20 \\
\hline Ex-smoker & 859 & 64 & 205 & 15 & 287 & 21 \\
\hline Current smoker & 1006 & 64 & 201 & 13 & 356 & 23 \\
\hline Mental stress: & & & & & & \\
\hline Not at all & 853 & 79 & 87 & 8 & 139 & 13 \\
\hline Little & 1269 & 67 & 267 & 14 & 355 & 19 \\
\hline To some extent & 855 & 58 & 260 & 17 & 367 & 25 \\
\hline Much & 203 & 45 & 74 & 16 & 173 & 39 \\
\hline Self assessed ability to wor & coming & year: & use of & sculo & al heal & \\
\hline No problems & 2085 & 80 & 309 & 12 & 224 & 8 \\
\hline Problems possible & 824 & 50 & 297 & 18 & 538 & 32 \\
\hline Problems likely & 103 & 29 & 46 & 13 & 209 & 58 \\
\hline
\end{tabular}

body mass index, stress, and self assessed ability to work (table 2). The mean values for other musculoskeletal pains were 0.34 among healthy workers, 0.55 among those with mild, and 1.93 among those with severe radiating neck pain.

MARGINAL MODEL

The final proportional odds model fitted by the generalised estimating equations method is shown in table 3. The proportional odds
Table 3 Odds ratios for explanatory variables of radiating neck pain among Finnish forest industry workers in 1992-5 (marginal model fitted by generalised estimating equations method, $n=5179$ )

\begin{tabular}{lll}
\hline & \multicolumn{2}{l}{ Radiating neck pain } \\
\cline { 2 - 3 } Explanatory variable & $O R$ & $95 \%$ CI \\
\hline Constants for three level response: & \\
$\quad$ Intercept 1 & 0.02 & 0.01 to 0.03 \\
$\quad$ Intercept 2 & 0.06 & 0.04 to 0.08 \\
Time: & & \\
1992 & 1.0 & \\
1993 & 0.9 & 0.8 to 1.0 \\
1994 & 1.1 & 1.0 to 1.2 \\
1995 & 0.7 & 0.7 to 0.8 \\
Sex: & & \\
Male & 1.0 & \\
Female & 1.4 & 1.0 to 1.8 \\
Age (y): & & \\
<35 & 1.0 & \\
35-44 & 1.2 & 1.0 to 1.4 \\
$45-54$ & 1.7 & 1.5 to 2.1 \\
55-64 & 1.8 & 1.4 to 2.3 \\
A &
\end{tabular}

Amount of twisting movements of the trunk during a work day: Not at all 1.0

Little

Moderate $\quad 2.9 \quad 1.0$ to 3.3

Much $3.5 \quad 1.9$ to 6.7

Working with a hand above shoulder level (h/day):

$<0.5 \quad 1.0$

$\begin{array}{lll}0.5-1 & 3.4 & 1.5 \text { to } 7.5\end{array}$

Balance of work demands:

2.20 .7 to 6.4

Good

Moderate

0.7 to 6.4

$1.0 \quad 1.0$ to 1.3

Overload at work:

Not at all

Little

1.0 to 1.3

Definite

Body mass index $\left(\mathrm{kg} / \mathrm{m}^{2}\right)$ :

$<23.0$

$23.0-25.9$

26.0-28.9

1.1 to 1.3

1.3 to 1.5

Smoking:

Non-smoker

Ex-smoker

Current smoker

1.1 to 1.5

Mental stress:

Not at all

Little

To some extent

1.0 to 1.3

1.2 to 1.7

1.2 to 1.7

Much

Other musculoskeletal pains (sum score):

Increment of one unit $\quad 2.3$

1.0 to 1.2

1.1 to 1.3

teractions:

Sex $\times$ age $(y)$ :

Male $x<35$

Female $\times 35-44$

Female $\times 45-54$

Female $\times 55-64$

Not at all $\times$ not at all

Little $\times$ little

Littlexto some extent

Littlexmuch

Moderatexlittle

$\begin{array}{ll}0.9 & 0.4 \text { to } 1.7\end{array}$

$\begin{array}{lll} & 0.8 & 0.4 \text { to } 1.5\end{array}$

Moderate $\times$ much

Much $\times$ little

\begin{tabular}{lll} 
Much $\times$ to some extent & 1.0 & 0.9 to 2.0 \\
\hline & 0.4 & 0.4 to 1.8
\end{tabular}

$\begin{array}{lll}\text { Much } \times \text { much } & 0.3 & 0.2 \text { to } 0.7\end{array}$

Twisting of the trunk $\times$ working with a hand above shoulder level (h/day):

Not at all $x<0$.

Little $\times 0.5-1$

Little $x>1$

Moderate $\times 0.5-1$

Moderate $x>1$

Much $\times 0.5-1$

$\operatorname{Much} \times>1$

$\begin{array}{ll}1.0 & \\ 0.4 & 0.2 \text { to } 0.9 \\ 0.8 & 0.3 \text { to } 2.5 \\ 0.3 & 0.2 \text { to } 0.8 \\ 0.6 & 0.2 \text { to } 1.8 \\ 0.3 & 0.1 \text { to } 0.6 \\ 0.6 & 0.2 \text { to } 1.7\end{array}$

assumption means that the odds ratios of the explanatory variables apply to all cut off points (at least mild radiating neck pain $v$ healthy, severe $v$ healthy or mild) of the response. The women had a 1.4-fold to 2.2-fold risk of 
Table 4 Effect (odds ratio) of sex on radiating neck pain in different age groups

\begin{tabular}{|c|c|c|c|c|}
\hline & \multicolumn{4}{|c|}{$\operatorname{Age}(y)$} \\
\hline & $<35$ & $35-44$ & $45-54$ & $55-64$ \\
\hline \multicolumn{5}{|l|}{ Sex: } \\
\hline Men (reference) & 1.0 & 1.0 & 1.0 & 1.0 \\
\hline Women & 1.4 & 2.2 & 1.7 & 1.4 \\
\hline
\end{tabular}

Table 5 Effect (odds ratio) of age on radiating neck pain according to sex

\begin{tabular}{lll}
\hline & \multicolumn{2}{c}{ Sex } \\
\cline { 2 - 3 } & Men & Women \\
\hline Age (y): & & \\
$<35$ (reference) & 1.0 & 1.0 \\
$35-44$ & 1.2 & 2.0 \\
$45-54$ & 1.7 & 2.2 \\
$55-64$ & 1.8 & 1.9 \\
\hline
\end{tabular}

radiating neck pain compared with men of the same age (table 4).

The effect of age on radiating neck pain was higher among the women than among the men. Among the men the risk of neck pain increased after the age of 45 . Among the women the risk of neck pain increased after the age of 35 (table 5).

The risk of radiating neck pain increased with increasing amount of twisting movements of the trunk. The effect of the amount of twisting movements of the trunk was dependent on working with a hand above shoulder level and stress. The effect was highest for those working with a hand above shoulder level for less than 0.5 hours a day and lowest for those working with a hand above shoulder level for $0.5-1$ hours a day. The effect of the amount of twisting movements decreased with increasing amount of stress.

The risk of radiating neck pain increased with increasing duration of working with a hand above shoulder level, except for those with no twisting movements of the trunk (table 6). The risk of radiating neck pain increased slightly with moderate or poor balance of work demands and overload at work.

Body mass index had an effect on radiating neck pain; subjects with an index above 26.0 $\mathrm{kg} / \mathrm{m}^{2}$ had a 1.4 -fold to 1.5 -fold risk compared with those with an index below $23.0 \mathrm{~kg} / \mathrm{m}^{2}$. Smokers had a slightly increased risk of radiating neck pain.

Mental stress had a strong effect on radiating neck pain. Among the subjects with no twisting movements of the trunk those with much stress had a sixfold risk of neck pain compared with those with no stress. The risk was twofold

Table 6 Effect (odds ratio) of working with a hand above shoulder level on radiating neck pain according to amount of twisting movements of the trunk

\begin{tabular}{lcccc}
\hline \multicolumn{5}{c}{ Amount of twisting movements of the trunk } \\
\cline { 2 - 5 } & Not at all & Little & Moderate & Much \\
\hline Working with a hand above shoulder level (h/day): & & \\
$<0.5$ (reference) & 1.0 & 1.0 & 1.0 & 1.0 \\
$0.5-1$ & 3.4 & 1.3 & 1.1 & 0.9 \\
$>1$ & 2.2 & 1.8 & 1.3 & 1.2 \\
\hline
\end{tabular}

Table 7 Odds ratios for explanatory variables of radiating neck pain among Finnish forest industry workers in 1992-5 (transition model, $n=3994$ subjects ( 8856 transitions))

\begin{tabular}{|c|c|c|}
\hline \multirow[b]{2}{*}{ Explanatory variable } & \multicolumn{2}{|c|}{ Radiating neck pain } \\
\hline & $O R$ & $95 \% C I$ \\
\hline \multicolumn{3}{|c|}{ Constants for three level response: } \\
\hline Intercept 1 & 0.06 & 0.05 to 0.08 \\
\hline Intercept 2 & 0.02 & 0.02 to 0.02 \\
\hline \multicolumn{3}{|c|}{$\begin{array}{l}\text { Previous radiating neck pain (days during preceding } 12 \\
\text { months): }\end{array}$} \\
\hline $0-7$ & 1.0 & \\
\hline $8-30$ & 5.3 & 4.5 to 6.3 \\
\hline$>30$ & 9.5 & 7.8 to 11.6 \\
\hline \multicolumn{3}{|l|}{ Time: } \\
\hline 1992 & 1.0 & \\
\hline 1993 & 0.9 & 0.8 to 1.0 \\
\hline 1994 & 0.6 & 0.6 to 0.7 \\
\hline \multicolumn{3}{|l|}{ Sex: } \\
\hline Male & 1.0 & \\
\hline Female & 1.4 & 1.2 to 1.6 \\
\hline \multicolumn{3}{|l|}{ Age $(y)$ : } \\
\hline$<35$ & 1.0 & \\
\hline $35-44$ & 1.4 & 1.2 to 1.6 \\
\hline $45-54$ & 1.7 & 1.4 to 1.9 \\
\hline $55-64$ & 1.4 & 1.1 to 1.8 \\
\hline
\end{tabular}

Working with the trunk in forward flexion (h/day):

$\begin{array}{lll}<1 & 1.0 & \\ 1-2 & 1.2 & 1.0 \text { to } 1.3 \\ >2 & 1.2 & 1.0 \text { to } 1.3\end{array}$

Working with a hand above shoulder level (hours/day)

$<0.5 \quad 1.0$

$0.5-1$

$>1$

$\begin{array}{ll}1.0 & 1.0 \text { to } 1.5\end{array}$

$1.6 \quad 1.3$ to 2.0

$<23.0$

$23.0-25.9$

$26.0-28.9$

$\geqslant 29.0$

Smoking:

Non-smoker

Ex-smoker

Mental stress:

Not at all

Little

$\begin{array}{lll}\text { To some extent } & 1.5 & 1.3 \text { to } 1.8 \\ \text { Much } & 1.7 & 1.4 \text { to } 2.0\end{array}$

Other musculoskeletal pains (sum score):

$\begin{array}{lll}\text { Increment of one unit } & 1.4 & 1.3 \text { to } 1.5\end{array}$

Self assessed ability to work during the coming 5 years because of musculoskeletal health:

$\begin{array}{lll}\text { No problems } & 1.0 & \\ \text { Problems possible } & 1.5 & 1.4 \text { to } 1.7 \\ \text { Problems likely } & 2.0 & 1.6 \text { to } 2.5\end{array}$

Problems likely

Interaction

Radiating neck pain in a previous questionnaire

(days) $\times$ working with a hand above shoulder level (h/day): $<8 \times<0.5$

$8-30 \times 0.5-1$

$8-30 \times>1$

$>30 \times 0.5-1$

1.0

0.6 to 1.2

$>30 \times 0.5-1$
$>30 \times>1$

0.6 to 1.2

0.6 to 1.1
0.4 to 0.8

$0.7 \quad 0.5$ to 0.9

among those with at least little twisting movements. Other musculoskeletal pains markedly increased the risk of radiating neck pain.

TRANSITION MODEL

Previous radiating neck pain was a strong predictor of current pain (table 7). It had an interaction with working with a hand above shoulder level. Among those who worked with a hand above shoulder level less than 0.5 hours a day, mild radiating pain in a previous questionnaire increased the risk of current pain fivefold, and previous severe radiating pain increased the risk almost 10 -fold. For those who worked with a hand above shoulder level more than 0.5 hours a day these effects were lower (table 8). 
Table 8 Effect (odds ratio) of radiating pain in a previous questionnaire on current radiating pain by working with hand above shoulder level

\begin{tabular}{lllc}
\hline & \multicolumn{3}{l}{$\begin{array}{l}\text { Working with a hand above shoulder level } \\
\text { (h/day) }\end{array}$} \\
\cline { 2 - 4 } & $<0.5$ & $0.5-1$ & $>1$ \\
\hline Radiating pain in a previous questionnaire (days/12 months): \\
0-7 (reference) & 1.0 & 1.0 & 1.0 \\
8-30 & 5.3 & 4.3 & 4.2 \\
$>30$ & 9.5 & 5.7 & 6.6 \\
\hline
\end{tabular}

Table 9 Effect (odds ratio) of working with a hand above shoulder level on radiating pain according to radiating pain in a previous questionnaire

\begin{tabular}{|c|c|c|c|}
\hline & \multicolumn{3}{|c|}{$\begin{array}{l}\text { Radiating pain in a previous questionnaire } \\
\text { (days/12 months) }\end{array}$} \\
\hline & $0-7$ & $8-30$ & $>30$ \\
\hline \multicolumn{4}{|c|}{ Working with a hand above shoulder level (h/day): } \\
\hline$<0.5$ (reference) & 1.0 & 1.0 & 1.0 \\
\hline $0.5-1$ & 1.2 & 1.1 & 1.0 \\
\hline$>1$ & 1.6 & 1.0 & 1.1 \\
\hline
\end{tabular}

The risk of radiating neck pain was higher among the women than among the men. The risk of radiating neck pain increased with increasing age until 45-54 years and decreased slightly in the oldest age group.

Working with the trunk in forward flexion slightly increased the risk of radiating neck pain.

Working with a hand above shoulder level increased the risk of radiating neck pain only among those who had not had previous radiating neck pain (table 9).

High body mass index and smoking increased the risk of radiating neck pain slightly. There was a dose-response relation between mental stress and radiating neck pain. A one unit increase in other musculoskeletal pains increased the risk of radiating neck pain 1.4-fold. Those anticipating problems in future ability to work had an increased risk of radiating neck pain.

\section{Discussion}

In our longitudinal study, we found that radiating neck pain was associated with some physical work load factors and several individual factors. We chose radiating pain as the outcome in our study, because we found that radiating neck pain was a more persistent symptom than local neck pain (data not shown). Moreover, we found in an earlier analysis that the risk estimates were higher for several factors when radiating neck pain was used as the outcome compared with local neck pain. ${ }^{15}$

Two methods of statistical analysis were used. The transition model was used in a predictive analysis by lagging the exposures by 1 year. The inclusion of the outcome from the previous year as an explanatory variable also enabled us to test for the interactions between previous radiating pain and the exposures of interest. For the proportional odds model run by the generalised estimating equations method we chose the outcome and the explanatory variables from the same year. The reason for this was that we assumed some of our explanatory variables - for example, mental stress and other musculoskeletal painshave fairly short term effects. Also the exposures to physical work load were assumed to have short term effects as well as long term effects. Moreover, having the exposure and outcome from the same year enabled us to use all our data in the analysis. We used multiplicative models; however, the interactions found suggested that some joint effects of the variables might be additive.

The risk of radiating neck pain was slightly higher for women than for men. This agrees with earlier studies ${ }^{3}$ and can be explained by biological factors - for example, lower force of the shoulder muscles among women. The variable, sex, can also entail work exposure factors that were not assessed in the study.

Higher age increased the risk of neck pain in both analyses of this study. In the model fitted by the generalised estimating equations method age had an interaction with sex, but in the transition model age had an independent effect on neck pain. The risk of radiating neck pain increased until the age of 55 and decreased slightly thereafter. The increase with age can be understood by increasing degeneration of the cervical spine with age. The decrease of radiating neck pain in the oldest age group is more difficult to explain. There was no selection out of the cohort according to age, neither was there selection according to previous radiating neck pain. One explanation could be that with advanced degenerative changes the spine restabilises and may become less painful.

Working with a hand above shoulder level was associated with radiating neck pain both in the model based on generalised estimating equations and the transition model. In the transition model there was, however, an interaction with previous radiating neck pain, indicating an increasing risk with increasing duration of such work only among the workers with healthy necks (incident neck pain). Working with a hand above shoulder level did not predict the persistence of radiating neck pain. Feedback bias (that subjects with neck pain may with time modify their work load, ${ }^{18}$ in this case working with a hand above shoulder level) may explain this finding.

The amount of twisting movements of the trunk was fairly strongly associated with radiating neck pain in the model based on generalised estimating equations, but not in the transition model. Also the balance of work demands was associated with radiating neck pain only in the model fitted by the generalised estimating equations method.

Most of the questions about work load had already been validated at the workplace. ${ }^{11}$ For some work postures we found that those with severe low back pain tended to overestimate the duration of the posture. If this holds true for radiating neck pain, the odds ratios for the postural factors may be somewhat overestimated in the model based on generalised estimating equations.

The result that the subjects reported less radiating neck pain in the 3 rd year of follow up than in the preceding questionnaires was 
somewhat unexpected, as they were then 3 years older than in the beginning of the follow up. It is possible that the 3 year follow up period was too short to show an effect of aging.

Body mass index was associated with radiating neck pain. Similar results were obtained in a Finnish normal population study in which clinically defined "chronic neck syndrome" was associated with body mass index. ${ }^{3}$ Biomechanical factors may explain the result to some extent. Metabolic factors might also be involved, as obesity has been associated with general osteoarthrosis. ${ }^{23}$

Smoking was weakly associated with radiating neck pain. Leino-Arjas showed in a 10 year prospective study that smoking predicted a change in neck and shoulder symptoms score, consisting of non-specific symptoms in the neck and shoulders and radiating neck pain. ${ }^{24}$

Mental stress was associated with radiating neck pain in both analyses, and it was an independent predictor in the transition model. To our knowledge this is the first prospective study to show evidence of mental stress as a predictor of neck symptoms. In an earlier study with four repeated questionnaire surveys carried out at 3 month intervals we saw a concurrent occurrence between neck symptoms and mental stress. ${ }^{25}$ Leino and Hänninen found that the sum score of "overstrain" (composed of mental strenuousness of work, extent of work concerns at home, and being overstrained by work) predicted the 10 year change in the 12 month score of symptoms of the neck, shoulder, and upper limbs among white collar men in the metal industry. ${ }^{13}$ In a previous report, Leino found that stress symptoms predicted musculoskeletal disorders 5 and 10 years later. ${ }^{26}$ Neck symptoms or disorders were not analysed separately in these studies. In a 24 year follow up study, high mental work load at the onset of the study was associated with disorders of the neck and shoulder region at the end of the follow up. Temporal relations remain obscure, as neck disorders were not assessed in the beginning of the study, and the follow up time was very long. ${ }^{27}$ The effect of stress is usually explained as being mediated through increased awareness and muscle tension.

Other musculoskeletal pains increased the risk of radiating neck pain. Similar musculoskeletal comorbidity has earlier been reported in cross sectional studies. ${ }^{328}$ Such comorbidity is best understood by common risk factors of the disorders, or their common pathomechanisms - such as degeneration - but other factors may also play a part.

Those anticipating problems in future ability to work because of musculoskeletal health had an increased risk of radiating neck pain in the transition model. This result shows the significance of subjective assessments in the prediction of health outcomes.

The lack of association between radiating neck pain and physical exercise is in agreement with some other studies. ${ }^{29}{ }^{30}$ In a prospective study, Pietri-Taleb et al found that physical exercise at least twice a week protected against neck trouble. ${ }^{6}$
Whether the subjects were working or not in the target enterprise at the time of the follow up assessments had no effect on radiating neck pain. In this study, most of those who were no longer employed by the enterprise were from the two oldest groups and were retired. Our result suggests that leaving work had no effect on radiating neck pain. Studies with workers in highly repetitive or static tasks have shown a decrease in neck disorders or symptoms after a major change in workload. ${ }^{131}$

The effects of some of the explanatory variables on the risk of radiating neck pain were small in this study. This reflects the multifactorial nature of radiating neck pain. The strong effect of previous radiating neck pain shows the chronic nature of this symptom. Previous pain may also reflect earlier effects of the other risk factors.

Our results suggest that more individual factors than work related factors are associated with radiating neck pain. This result may be partly due to a greater accuracy of some of the individual factors. Factors such as sex, age, and body mass index involve almost no error, whereas the assessment of the duration of certain work postures each day is only moderately valid at best. Error in the assessment of exposure usually attenuates the effect.

The response rates to the four questionnaires were fairly high. Yet, those who replied to all four questionnaires represented only $43 \%$ of the originally selected cohort of 7000 subjects. We think that is is difficult to achieve higher response rates in this type of repeated measurements study. We judged that we could not send questionnaires to the subjects who had not replied to the previous questionnaire after two reminders.

To see how our study population might have been selected we compared the outcome and the explanatory variables from the previous year between the respondents and nonrespondents. We found no differences in radiating neck pain and only minor differences in age and sex distribution, and leaving versus continuing employment. Yet the nonrespondents more often anticipated difficulties at work during the coming 5 years than the respondents due to musculoskeletal health, suggesting that there might have been some health based selection in our study population. This may have violated the missing completely at random requirement in our analyses and caused some bias to our estimates.

It is concluded that, of factors amenable to change, working with a hand above shoulder level, mental stress, being overweight, and smoking were consistently associated with radiating neck pain. Measures to prevent workers from being overweight should therefore be directed to both physical work load factors and factors that may cause stress. Prevention of being overweight may reduce neck pain as well as its other beneficial effects. Radiating neck pain is a persistent symptom and often coexists with other musculoskeletal symptoms.

We acknowledge the Finnish Work Environment Fund for financial support. 
1 Jonsson BG, Persson J, Kilbom Å. Disorders of the cervicobrachial region among female workers in the electronics industry. Inter

2 Tola S, Riihimäki H, Videman T, et al. Neck and shoulder symptoms among men in machine operating, dynamic physical work and sedentary work. Scand $\mathcal{f}$ Work Environ Health 1988;14:299-305.

3 Mäkelä M, Heliövaara $M$, Sievers $K$, et al. Prevalence, determinants, and consequences of chronic neck pain in Finland. Am f Epidemiol 1991;134:1356-67.

4 Holmström EB, Lindell J, Moritz U. Low back and neck/shoulder pain in construction workers: occupational workload and psychosocial risk factors. Part 2: Relationship to neck and shoulder pain. Spine 1992;17:672-7.

5 Ekberg K, Björkqvist B, Malm P, et al. Case-control study of risk factors for disease in the neck and shoulder area. Occup Environ Med 1994;51:262-6.

6 Pietri-Taleb F, Riihimäki H, Viikari-Juntura E, et al. Longitudinal study on the role of personality characteristics and tudinal study on the role of personality characteristics and psychological distress

7 Viikari-Juntura E, Riihimäki H, Tola S, et al. Neck trouble in machine operating, dynamic physical work and sedentary work: a prospective study on occupational and individual risk factors. $\mathcal{F}$ Clin Epidemiol 1994;47:1411-22.

8 Kilbom Å, Persson J, Jonsson BG. Disorders of the cervicobrachial region among female workers in the electronics industry. International fournal of Industrial Ergonomic 1986;1:37-47.

9 Ohlsson K, Attewell RG, Pålsson B, et al. Repetitive industrial work and neck and upper limb disorders in females. Am f Ind Med 1995;27:731-47.

10 Wiktorin C, Karlqvist L, Winkel J, et al. Validity of self reported exposures to work postures and manual materials handling. Scand 7 Work Environ Health 1993;19:208-14.

11 Viikari-Juntura E, Rauas S, Martikainen R, et al. Validity of self reported physical work load in epidemiologic studies on musculoskeletal disorders. Scand f Work Environ Health on musculoskel

12 Bongers PM, de Winter CR, Kompier MA, et al. Psychosocial factors at work and musculoskeletal disease. Scand $\mathcal{F}$ Work Emviron Health 1993:19:297-312.

13 Leino PI, Hänninen V. Psychosocial factors at work in relation to back and limb disorders. Scand $\mathcal{F}$ Work Environ Health 1995;21:134-42.

14 Kuorinka I, Jonsson B, Kilbom Å, et al. Standardised Nordic questionnaires or the analysis of musculoskeletal symptoms. Appl Ergon 1987;18:233-7.
15 Viikari-Juntura E, Riihimäki H, Takala E-P, et al. Niskahartiaseudun ja yläraajan kipuja ennustavat tekijät metsäteollisuudessa (Factors predicting pain in the neck, shoulders, and upper limbs in forestry work). Työ ja ihminen 993;7:233-53. (in Finnish with English summary.)

16 Elo A-L, Leppänen A, Lindström K, et al. Occupational stress questionnaire: user's instructions. Helsinki: Institute of Occupational Health, 1992. (Review 19.)

17 Diggle P, Liang K-Y, Zeger SL. Analysis of longitudinal data. Oxford: Clarendon Press, 1994

18 Eisen EA. Methodology for analyzing episodic events. Scand 7 Work Environ Health 1999;25(suppl 4):36-42.

19 Liang KY, Zeger SL. Longitudinal data analysis using generalized linear models. Biometrika 1986;73:13-22.

20 Zeger SL, Liang KY. Longitudinal data analysis for discrete and continuous outcomes. Biometrics 1986;42:121-30.

21 Shah BV, Barnwell BG, Bieler GS. SUDAAN user's manual, release 7.11. Research Triangle Park, NC: Research Triangle Institute, 1996.

22 Harrel FEJ, Lee KL, Mark DB. Multivariable prognostic models: issues in developing models, evaluating assumptions and adequacy, and measuring and reducing errors. Stat Med 1996;15:361-87.

23 Felson DT. Epidemiology of hip and knee osteoarthritis. Epidemiol Rev 1988;10:1-28.

24 Leino-Arjas P. Smoking and musculoskeletal disorders in the metal industry: a prospective study. Occup Environ Med 1998;55:828-33.

25 Takala EP, Viikari-Juntura E, Moneta GB, et al. Seasonal variation in neck and shoulder symptoms. Scand $\mathcal{F}$ Work Environ Health 1992;18:257-61.

26 Leino P. Symptoms of stress predict musculoskeletal disorders. F Epidemiol Community Health 1987;43:293-300.

27 Fredriksson K, Alfredsson L, Köster M, et al. Risk factors for neck and upper limb disorders: results from 24 years of follow up. Occup Environ Med 1999;56:59-66.

28 Luopajärvi T, Kuorinka I, Virolainen $M$, et al. Prevalence of tenosynovitis and other injuries of the upper extremities in repetitive work. Scand f Work Environ Health 1979;5:4855 .

29 Linton SJ. Risk factors for neck and back pain in a working population in Sweden. Work Stress 1990;4:41-9.

30 Hales TR, Sauter SL, Peterson MR, et al. Musculoskeletal disorders among visual display terminal users in a telecommunications company. Ergonomics 1994;37:1603-21.

31 Schibye B, Skov T, Ekner D, et al. Musculoskeletal symptoms among sewing machine operators. Scand $\mathcal{f}$ Work Environ Health 1995;21:427-34.

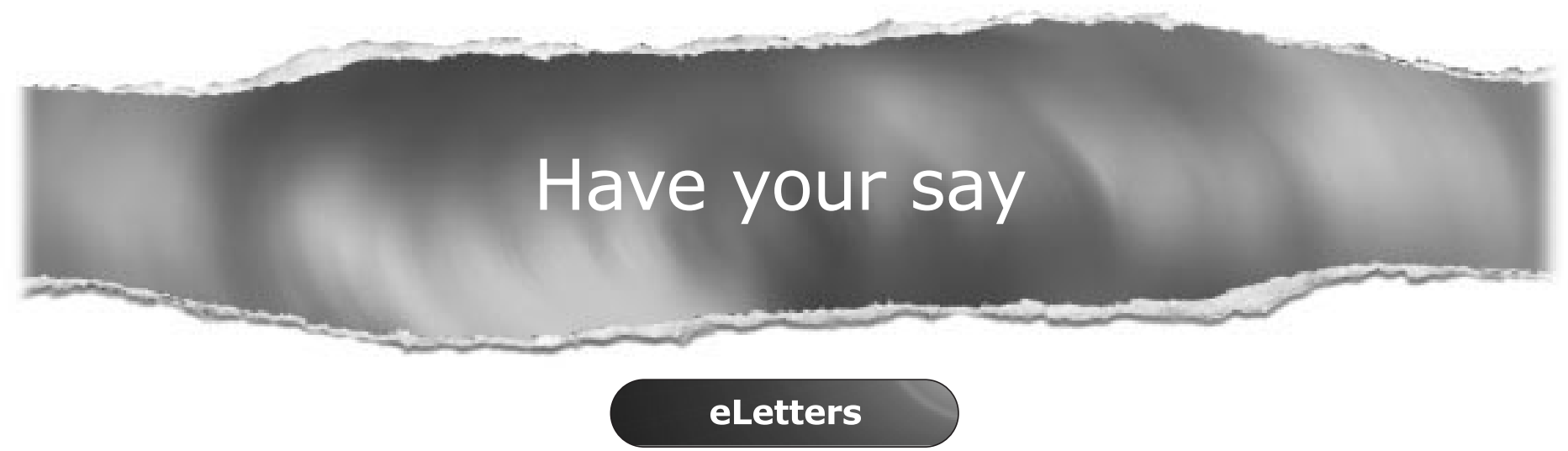

If you wish to comment on any article published in Occupational and Environmental Medicine you can send an eLetter using the eLetters link at the beginning of each article. Your response will be posted on Occupational and Environmental Medicine online within a few days of receipt (subject to editorial screening).

www.occenvmed.com 